\title{
Ensinando Geometria a Deficientes Visuais: o ambiente dinâmico Geometrix
}

\section{Teaching geometry to visually impaired people: the dynamic environment Geometrix}

\author{
Lidiane Figueiras Silva \\ José Antonio Borges \\ Núcleo de Computação Eletrônica \\ Universidade Federal do Rio de \\ Janeiro \\ lidiane.figueira@gmail.com \\ antonio2@nce.ufrj.br
}

\author{
Cabral Lima \\ Instituto de Matemática \\ Universidade Federal do Rio de \\ Janeiro \\ cabrallima@ufrj.br
}

\author{
Adriana Benevides Soares \\ Universidade do Estado do Rio de \\ Janeiro \\ Universidade Salgado de Oliveira \\ adriana.benevides@pq.cnpq.br
}

Resumo Esta publicação mostra uma pesquisa original sobre o ensino de geometria a deficientes visuais. O Geometrix, um novo ambiente dinâmico especialmente concebido e implementado para esse fim, é detalhado, assim como um estudo de campo efetuado com um grupo de controle composto por sujeitos normovisuais e um grupo de experimentação composto por sujeitos deficientes visuais. Os resultados deste estudo confirmaram a hipótese de que a utilização de ambientes computacionais dinâmicos na educação de deficientes visuais pode corroborar na edificação, retenção e aplicação de conceitos abstratos. O empenho em desenvolver um ambiente pragmático e adequado aos aspectos sui generis de seus usuários embasaram os propósitos sedimentais de se prover uma aprendizagem peremptória e autônoma de conceitos de geometria, assim como proporcionar aplicações apropriadas desses conceitos em processos de ensino e aprendizagem. Os resultados também mostraram que o Geometrix pode ajudar deficientes visuais a aprimorarem seus posicionamentos espaciais. Análises comparativas sobre tempo de aquisição de conceitos geométricos por deficientes visuais levaram à conclusão que o ambiente tem uma performance assaz superior ao ensino tradicional em sala de aula.

Palavras-Chave: ensino de geometria, deficientes visuais, ambiente computacional dinâmico.

\begin{abstract}
This paper shows an original research on the teaching of geometry for visually impaired people. Geometrix, a new dynamic environment specially designed and implemented for this purpose, is detailed as well as a field research conducted with a control group of sighted people and an experimental group of visually impaired people. The results of this research established the hypothesis that the use of dynamic computing environments in the education of visually impaired people can help the development, retention and application of abstract concepts. The commitment to develop an pragmatic and adequate environment in regard to the sui generis characteristics of its users supported the foremost purposes of providing peremptory and autonomous learning of geometric concepts, as well as providing adequate applications of these concepts in teaching and learning processes. The results also showed that Geometrix can help visually impaired people to improve their spatial positions. Comparative analyses on time of acquisition of geometric concepts by visually impaired people have concluded that the environment has a better performance than the traditional teaching in classrooms.
\end{abstract}

Keywords: teaching of geometry, visually impaired people, dynamic computing environment. 


\section{Introdução}

O principal objetivo deste artigo é mostrar que a utilização de ambientes computacionais dinâmicos na educação de deficientes visuais (DV) pode corroborar substancialmente na edificação, retenção e aplicação de conceitos abstratos. Para atingir esse objetivo este artigo descreve o novo ambiente computacional dinâmico Geometrix e um estudo de campo associado que foi especialmente realizado para validação de conceito da proposta. Um resultado importante obtido foi que o uso efetivo desse ambiente por DV corrobora para uma aprendizagem peremptória de conceitos geométricos e fortalece a adequação de aplicações a posteriori desses conceitos em escopos de ensino e aprendizagem. Um resultado colateral benéfico dimanado da presente pesquisa concerne à possibilidade de usar o Geometrix como um coadjuvante indutor do posicionamento espacial de DV em ambientes do mundo real. O estudo de campo utilizou um instrumento descritivo-interpretativo e uma análise fundamentalmente qualitativa de caráter interpretativo. A opção por essa abordagem foi norteada por asserções importantes estabelecidas por alguns teóricos ([2], [3]). Geometrix é um ambiente computacional dinâmico original que possui duas virtudes essenciais: é de baixíssimo custo e de simplória instalação. A despeito de haver sido criado especialmente para DV, alguns experimentos paralelos ao estudo de campo, com videntes, apontaram para a possibilidade de uso desse novo ambiente como um facilitador para processos de ensino e aprendizagem de conceitos geométricos em escopos normovisuais.

A pesquisa para o desenvolvimento do Geometrix foi efetuada durante três anos e decomposta em quatro etapas metodológicas principais: $i$. Estudo Observacional; ii. Estudo Exploratório; iii. Aplicação Discente; iv. Aplicação Docente Contextual. A etapa concernente ao estudo observacional (i) foi efetuada no Instituto Benjamin Constant (IBC) [1] e a finalidade principal foi a de colher subsídios para a fase de análise de requisitos. Observouse atentamente para os procedimentos tradicionais utilizados no ensino de geometria para DV a fim de se poder entender o universo educacional e, assim, se identificar a dinâmica de ativação dos processos de ensino e aprendizagem. O estudo exploratório (ii) representa essencialmente o desenvolvimento recorrente do Geometrix, no qual as etapas de projeto, implementação e teste se alternaram ciclicamente, no tentame de se prover usabilidade compatível com o perfil sui generis dos futuros usuários. É importante ressalvar que o termo usabilidade empregado neste artigo refere-se a um conceito mais dilatado que busca apenas definir a facilidade com que as pessoas podem utilizar uma ferramenta para realizar uma tarefa específica, e não referencia um estudo teórico com base em teorias de usabilidade. Uma bateria suplementar de testes-finais, que exigiu aplicações com diferentes conjunturas, foi efetivada visando avalizar a adequação ao uso e à coerência do sistema. A etapa de aplicação discente (iii) concerniu ao estudo de campo propriamente dito, usando um grupo de controle composto por alunos sem deficiência visual, e um grupo experimental composto por alunos DV. A aplicação docente contextual (iv), que foi fundamental para as conformações pragmáticas do Geometrix, foi efetivada através do uso intensivo do sistema por um professor (mestre em ciência da computação pela UFRJ) com perda total de visão. A criteriosa execução dessas quatro etapas levou à confirmação da principal hipótese desta pesquisa de que, sob um prisma amplo, a utilização de ambientes computacionais dinâmicos pode ajudar na edificação, fixação e aplicação de conceitos abstratos, e, sob um prima mais adstrito, o uso do Geometrix pode auxiliar substancialmente a alunos cegos (ou com acentuada deficiência visual) em suas elaborações e aplicações de conjecturas geométricas.

$\mathrm{O}$ restante deste artigo encontra-se dividido da seguinte forma: a seção 2 apresenta a fundamentação teórica advinda da análise de pesquisas precedentes abordando ambientes computacionais e que alicerçam-se sobre teorias basais da temática aqui abordada, tanto no que concerne ao ensino da geometria quanto no que concerne à acessibilidade e formação de DV; a seção 3 detalha o Geometrix sob o prisma de projeto e implementação modular de um sistema computacional de per si e, adicionalmente, sob o prisma educacional/tecnológico de seu uso por deficientes visuais; a seção 4 descreve o estudo de campo e a metodologia adotados para a avaliação de conceito da proposta; a seção 5 mostra a análise dos resultados e considerações correlatas; a seção 6 delineia as conclusões e propõe trabalhos futuros visando o aprimoramento do ambiente.

\section{Fundamentação teórica: tecnologias assistivas na matemática e na geo- metria para DV}

Os cientistas de informática na educação são cônscios de que já encontram-se dissipadas todas as dúvidas concernentes às potencialidades da utilização de ambientes computacionais no ensino e na aprendizagem. $\mathrm{O}$ foco tem se deslocado irrevogavelmente mais para a maneira de como usar esses ambientes do que para o questionamento (atualmente quase anacrônico) se eles são benéficos ou não para os processos de ensino e aprendizagem. Os hodiernos esforços de pesquisas têm apontado mais para o "como aplicar" esses ambientes uma vez que é preciso levar em consideração que eles devem ser consonantes com a transitoriedade e ativação dos processos durante uma sessão de ensino e aprendizagem, sem que, entre 
outras coisas, sejam infringidos critérios de objetividade e de efetiva eficiência pedagógica. Ou seja, a zetética vem se deslocando progressivamente da questão de se ambientes computacionais são ou não propícios aos processos de ensino e aprendizagem para a investigação de como esses ambientes podem ser mais favoravelmente (e adequadamente) utilizados nesses processos.

\subsection{Ensino da matemática}

A matemática tem por reconhecida característica o fato de ser habitualmente apontada como uma disciplina difícil de ser estudada, complexa de ser aprendida e implexa de ser ministrada. As questões centrais alusivas ao uso de ambientes computacionais nos processos de ensino e aprendizagem da matemática, no entanto, já se encontram assaz debatidas pois têm sido foco de diversas pesquisas, especialmente após o profuso surgimento de vários ambientes computacionais destinados a muitas subáreas da matemática [11]. Não obstante, ensinar matemática para DV ainda é um desafio abissal. Diferente de texto (que tem natureza linear e padrões unificados, como acontece na codificação Braille), a representação matemática possui estruturas intricadas que dificultam a tradução e retenção por parte de DV. Com efeito, a complexidade de expressões, as múltiplas dimensionalidades, a não-linearidade, as inúmeras semânticas e notações, a natureza espacial e as variadas formas de se expressar uma ideia são o grande desafio para DV representarem,

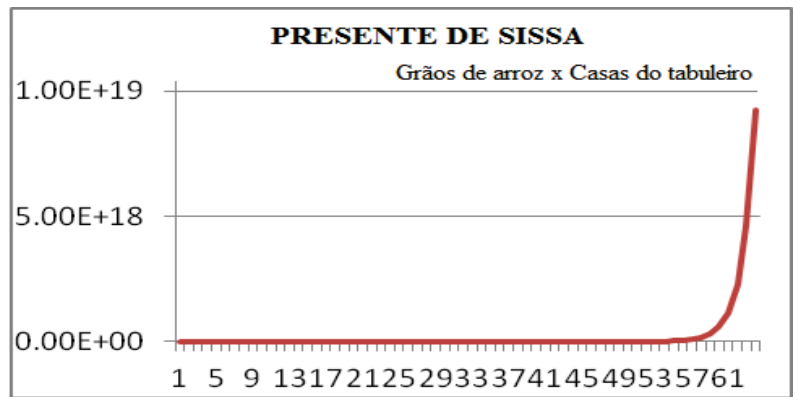

interpretarem e manipularem a matemática.

Figura 1: Progressão geométrica de grãos de arroz

A história da criação do jogo de xadrez é um bom exemplo desse desafio. A história do lendário membro da casta sacerdotal hindu Sissa Ben Dahir (que apresentou o seu novo jogo ao rajá Sharim) é intuitivamente fácil de entender por videntes e DV, desde que estes possuam a representação mental de um tabuleiro de xadrez. Por insistência do rajá, Sissa pediu uma recompensa: um grão de arroz na primeira casa do tabuleiro, dois grãos na segunda casa e assim por diante (em cada casa o dobro do número anterior de grãos: a progressão geométrica mostrada na Figura 1). Na décima casa estariam 512 grãos de arroz, na vigésima 1048576 e na última $9223372036854775808\left(9,22 \times 10^{18}\right)$ grãos. Tomando-se como $20 \mathrm{mg}$ a massa de 01 grão de arroz, o que o velho filósofo pediu foi aproximadamente 368800000000 (368,8 bilhões) toneladas de arroz. Sabendo-se que a produção mundial de arroz de 2007 foi de 645 milhões de toneladas, a recompensa de Sissa demoraria em torno de 572 anos para ser produzida nos dias atuais (nos quais, claro, a produção mundial desses grãos é muito superior àquela dos tempos de Sharim). Intuitivamente é assaz fácil para um deficiente visual entender a semântica por trás desse relato, mas compreender a formulação e a simbolização matemática do relato é tarefa um pouco mais árdua. De fato, ainda que muito simples para normovisuais, o cálculo final do valor total de grãos demandados por Sissa se expressa através de conceitos matemáticos que, para um deficiente visual, não são geralmente aprendidos de maneira natural. Com feito, a formulação matemática que fornece a soma $\mathrm{S}$ dos termos de uma progressão geométrica com razão $\mathrm{q} \neq 1$ é:

$$
\mathrm{S}=1+\mathrm{q}+\mathrm{q}^{2}+\mathrm{q}^{3}+\ldots+\mathrm{q}^{\mathrm{n}}
$$

multiplicando (1) por q em ambos os lados:

$$
\mathrm{qS}=\mathrm{q}+\mathrm{q}^{2}+\mathrm{q}^{3}+\mathrm{q}^{4}+\ldots+\mathrm{q}^{\mathrm{n}+1}
$$

subtraindo (1) de (2) obtém-se:

$$
\mathrm{qS}-\mathrm{S}=\mathrm{q}^{\mathrm{n}+1}-1
$$

ou seja:

$$
S=\frac{q^{n+1}-1}{q-1}
$$

que, para o caso de Sissa, vale:

$$
\sum_{i=0}^{63} 2^{i}
$$

A compreensão, retenção e aplicação de conceitos matemáticos são a condição sine qua non para o desenvolvimento do raciocínio matemático. Incutir raciocínio matemático é considerada tarefa árdua para professores em sala de aula com alunos normovisuais e, decerto, uma azáfama ainda mais intricada com alunos DV. Resumidamente, pode-se dizer que as principais causas dessas dificuldades são:

$i$. as expressões matemáticas estão em estruturas nãolineares (índices, frações, símbolos etc.). Até as mais simples podem ser abstrusas de compreensão via uma leitura em voz como, por exemplo, "um mais três dividido por dois mais cinco":

$$
\frac{1+3}{2+5}
$$

Poder-se-ia entender "um mais, três dividido por dois, mais 5", uma expressão valorada de forma bem distinta: $1+(3 / 2)+5$; 
ii. A linearidade da escrita Braille dificulta representar diretamente estruturas matemáticas;

iii. A escrita Braille não permite a correção de erros com a facilidade da escrita cursiva: o processo requer uma representação mental de um conceito antes mesmo de iniciar sua escrita (se isso não for feito, a escrita deverá ser refeita);

$i v$. A maioria dos professores de matemática recebe pouca (ou nenhuma) orientação acadêmica sobre como selecionar e aplicar metodologias específicas e direcionadas a DV.

Os trabalhos desenvolvidos no contexto de ensino e aprendizagem de DV adotam frequentemente duas metodologias: a estática, que usa essencialmente o código Braille para tentar traduzir conceitos através de codificações (por vezes estendidas), e a dinâmica na qual o áudio é considerado fundamental para a tradução desses conceitos. [27] e [28] ilustram o uso da metodologia estática enquanto [29] e [30] o da metodologia dinâmica. Diferentemente dessas pesquisas, a proposta aqui apresentada não está fundamentada em prover aos DV os resultados de suas interações com softwares dispendiosos, mas sim em permitir aos DV entenderem e manipularem corretamente conceitos geométricos. Com efeito, o Geometrix é um ambiente de baixíssimo custo que proporciona aos DV a habilidade de manipular matemática e não apenas de "ler" ou ouvir a matemática. A ideia basilar é, portanto, a de propor aprendizado através de autênticas manipulações de conceitos geométricos. Ademais, apesar de haver uma gama de trabalhos na área de disponibilidade e usabilidade para pessoas com diversos tipos de deficiência, não existem muitas contribuições pragmáticas para o ensino da matemática para DV. O trabalho aqui apresentado se insere precisamente neste escopo e pode ser visto como um suporte para futuras pesquisas envolvendo o acesso e a manipulação da matemática por DV através de sistemas computacionais de baixíssimo custo.

\subsection{Ensino da geometria}

Dentre as subáreas da matemática, a geometria tem tido uma posição destacada porque tem sido o foco preferido de ambientes computacionais de ensino e aprendizagem de matemática. Estes ambientes são habitualmente referenciados como ambientes de geometria dinâmica, ainda que, mais recentemente, a geometria dinâmica tem sido também designada como geometria interativa [4], notadamente quando se alude a ambientes dedicados a dispositivos móveis [5]. De uma maneira conceitual, ambientes de geometria dinâmica permitem construções gráficas e manipulações espaciais de sólidos e curvas geométricos. Para isto eles frequentemente proveem dispositivos de régua e compasso virtuais e alguns recursos suplementares (estes também corriqueiramente presentes em ambientes de outras subáreas da matemática).
Para DV, explorar gráficos, diagramas, linhas, curvas etc. representa uma grande dificuldade que pode ser atenuada se houver a possibilidade de ferramentas que permitam tornar tátil a exploração desses conceitos. Há que se admitir, portanto, que a geometria, por suas especificidades espaciais, é particularmente complexa a ser ensinada a DV. Por outro lado, é a geometria uma ferramenta extremamente importante na capacitação para a edificação de representações mentais, uma prerrogativa essencial nos deslocamentos físicos de DV. O ensino de geometria requer normalmente conjunturas visuais e deslocamentos espaciais de figuras, duas habilidades inexoravelmente implexas para DV, ainda que deslocamentos espaciais possam vir a ser feitos de forma exclusivamente mental. Um ambiente computacional que proporcione a aprendizagem de conceitos geométricos e a possibilidade de se construir e manipular objetos geométricos pode corroborar incisivamente tanto para o desenvolvimento da habilidade espacial quanto para a reificação dessa habilidade em contextos reais que exijam deslocamentos físicos. Ademais, esse tipo de ambiente auxilia na edificação, fixação e aplicação de conceitos abstratos, além de corroborar para o aprimoramento do raciocínio lógico e para a resolução de problemas de matemática. Trabalhos de pesquisa direcionados ao estudo de aplicações de novas tecnologias em processos de ensino e aprendizagem têm ressaltado que a aplicação de ambientes de geometria dinâmica em sala de aula pode ser uma forte aliada na resolução de problemas enfrentados no ensino da geometria e da trigonometria ([11], [12], [13], [14], [15]). Ainda que possam existir questionamentos sobre se a trigonometria faz parte da álgebra ou da geometria, parece mais intuitivo pensar que a trigonometria relaciona-se com as duas. Na realidade, diversas subáreas da matemática apresentam uma interconexão dialógica e integrativa uma vez que elas se auxiliam mutuamente na observação e interpretação de fatos e leis naturais. A geometria provê as configurações visuais essenciais para a compreensão dos conceitos da trigonometria. No entanto, à medida que esses conceitos são compreendidos eles podem ser incorporados a fórmulas e, por consequência, ao universo da álgebra. Embora a trigonometria tenha nascido bem antes da álgebra [16], sua aprendizagem só teria a ganhar com esta fusão tanto nas conceitualizações abordadas pela geometria em benefício da álgebra quanto na eliminação do formalismo demasiado da álgebra ao abordar a geometria. Sob esse prisma, a resolução de triângulos passaria a ser única parte genuinamente trigonométrica posto que se pode encaixar o resto biunivocamente na álgebra e na geometria.

Entre os ambientes de geometria dinâmica mais utilizados em processos de ensino e aprendizagem podem ser destacados o GeoGebra [6], o Tabulae [7], o Cabri Géomètre ([10]) e o Geometer's Sketchpad [9]. Como o nome indica, o GeoGebra faz precisamente uma fusão de 
álgebra com geometria, notadamente relacionando figuras geométricas às suas representações algébricas. Uma equação algébrica editada no ambiente faz surgir a figura geométrica associada, e uma alteração nesta equação (ou no conjunto de coordenadas associado) altera automaticamente a figura. $\mathrm{O}$ Tabulae tem como predicado principal o suporte a atividades colaborativas, via redes de computadores, utilizando conceitos e objetos matemáticos. A elaboração de gráficos de funções (polinomiais, logarítmicas, trigonométricas etc.) que podem ser alteradas e observadas em tempo real, juntamente com os objetos geométricos correlacionados, é uma reconhecida virtude do Tabulae. O Cabri Géomètre é especialmente voltado para o ensino da trigonometria pois possui bastante facilidades para a resolução de triângulos. Ele também inclui a animação de figuras geométricas e ferramentas para demonstrar as relações entre pontos de uma figura. A plataforma dual desse ambiente (Windows e Mac-Os) e a possibilidade de poder converter arquivos em Java têm corroborado para que este ambiente seja amplamente utilizado. O Geometer's Sketchpad tem por maior potencial o aprendizado de gradientes, transformações geométricas e aritmética de inteiros, embora ele permita também o estudo de figuras geométricas através de propriedades de medida e correlações. Um ponto forte deste ambiente são as ferramentas para se trabalhar com propriedades de ângulos e polígonos. Em termos gerais, ainda que assaz divulgados e bastante utilizados em processos de ensino e aprendizagem da geometria, esses ambientes computacionais de geometria dinâmica, assim como a quase totalidade dos ambientes computacionais, não se preocupam muito em usar tecnologias assistivas e, diferentemente do Geometrix, não podem ser utilizados facilmente por DV.

\subsection{Tecnologias assistivas}

O termo tecnologia assistiva já tem mais de vinte anos, tendo sido utilizado pela primeira vez no IDEA 1990 (special education law Individuals with Disabilities Education Act) [23], mas o uso consistente de tecnologias assistivas pode ainda ser considerado bastante baixo [24]. Nos USA apenas 59\% dos $71 \%$ dos estudantes que são DV e que poderiam se beneficiar de tecnologia assistiva têm oportunidade concreta de usá-la [25]. O custo (o fator primordial) e o fato da maioria dos professores não as reputar como importantes (para suas tarefas letivas) colocam as tecnologias assistivas como ferramentas de pouca significância e uso nos contextos de sala de aula. Não obstante, quanto mais equipamentos assistivos forem desenvolvidos (com baixo custo) maior serão suas aplicabilidades nos processos de ensino e aprendizagem de DV. Portanto, incentivar o desenvolvimento de pesquisas e equipamentos que lançam mão de tecnologias assistivas significa destarte educar melhor os DV. Assim sendo, muitos educadores e pesquisadores da informática aplicada ao ensino adotam ações que resultam na qualificação educacional de pessoas com deficiência.

A década de 80 foi palco do surgimento das primeiras tecnologias assistivas no Brasil, mas somente nos anos 90 que os leitores de tela, impressoras Braille, sintetizadores de voz e, sobretudo, o sistema Dosvox [31] deram impulso ao uso efetivo. Isto permitiu que DV pudessem ter um expressivo enriquecimento de seus processos de ensino e aprendizagem. Particularmente no que concerne à geometria, no entanto, as tecnologias assistivas criadas pouco ou quase nada ajudaram pois, em sua maioria, elas não possuíam funcionalidades permitindo a um deficiente visual entender e produzir naturalmente desenhos geométricos. Isto restringiu o aprendizado de DV a ser exclusivamente tátil e sem vinculações significativas com tecnologias computacionais. Ainda no plano nacional, a primeira tentativa de desenvolver um sistema computacional para auxiliar DV na elaboração de figuras geométricas, ao que se sabe, foi o editor de desenhos Desenvox [32], cuja interação com o usuário era a síntese de voz herdada do Dosvox. Nesse sistema a edição de um desenho envolve a colocação de elementos sobre um painel planar (em coordenadas selecionadas) e modificações posteriores sobre esses elementos. A colocação envolve basicamente um processo de informar as coordenadas do objeto enquanto a modificação de um elemento é tarefa mais complexa porque se faz necessário localizar o elemento desejado dentre os existentes. Diferentemente do Geometrix, toda entrada feita no Desenvox era via o teclado, com feedback sonoro, e não possuía um ambiente desenvolvido especialmente para aprendizagem de conceitos geométricos. O Desenvox foi descontinuado (in veritas, seu uso efetivo exigia que o aluno portasse consigo uma impressora Braille), e a lacuna por uma ferramenta que desse certa autonomia ao usuário deficiente visual, auxiliando-o na aquisição de conceitos geométricos, ficaria aberta em nosso grupo de pesquisa até o desenvolvimento do Geometrix. O Geometrix une elementos físicos e lógicos, tais como WEBCAM e técnicas de computação gráfica normalmente utilizadas em programas de realidade aumentada, num ambiente único usando tecnologias assistivas computacionais.

\subsection{Pesquisas correlatas}

Pesquisas correlacionando os processos de ensino e aprendizagem à capacitação de pessoas portadoras de deficiência têm sido desenvolvidas nesses últimos anos. Por exemplo, [17] apresenta um estudo sobre a interação do computador no processo de ensino e aprendizagem de pessoas com deficiência. [18] explora o uso de um jogo voltado para a memorização de cores e sons emitidos a partir de objetos virtuais projetados no mundo real visando o desenvolvimento cognitivo motor de crianças com 
necessidades especiais. Esse jogo lança mão de realidade aumentada, uma tecnologia que vem sendo bastante difundida notadamente com aplicabilidade em sistemas assistivos/adaptativos [21]. Interfaces adaptativas em softwares que possuam alto grau de usabilidade e atendam algumas necessidades de uma criança autista são apresentadas em [22], cujo objetivo principal é tentar aprimorar o desenvolvimento cognitivo de crianças autistas através de atividades lúdicas.

No universo de pesquisas correlatas cujo público alvo são DV, [47] discorre sobre o Mapavox, um sistema de controle de maquetes geográficas táteis, e mostra que o uso de feedback com síntese de Vox proporciona um ganho na percepção de relações geométricas. [33] aborda o uso de recursos de acessibilidade para auxiliar DV na navegação de um editor de diagramas e tem por objetivo central permitir a construção de diagramas UML (Unified Modeling Language) sem auxílio de outrem e, para atingir esse objetivo, usa o editor de diagramas GEDE ( $\boldsymbol{G E}$ neric Diagram Editor). [34] apresenta uma ferramenta de apoio ao processo de aprendizagem de banco de dados para DV, mais especificamente para o desenho de diagramas de entidade-relacionamento (DER). Essa ferramenta é integrada a um sintetizador de voz que fornece ao usuário as opções disponíveis cada vez que o usuário quer construir e/ou alterar um DER. Essa ferramenta poderia ser considerada como facilitadora pois não possui especificidades de tutoria. [35] propõe um protótipo de interface visando viabilizar o uso do mouse por DV. Para isto ele usa um editor de textos com menus reescritos visando prover a interface com o usuário, embora restrinja a distribuição de objetos expostos na tela a uma padronização bastante específica. [36] oferece meios eficazes para DV iniciarem ou aperfeiçoarem a digitação no teclado, baseado num feedback contínuo com síntese de voz. É fundamentado nos antigos cursos de datilografia e tem por meta principal fazer DV minimizarem o tempo de toques no teclado.

Ainda que a pesquisa descrita em [17] mencione a existência de sintetizadores de voz e teclados em Braille, ela difere da pesquisa aqui apresentada porque aborda substancialmente a deficiência mental e os principais resultados concernem à aplicação da informática como uma ferramenta para a melhoria da aquisição de conteúdos por alunos com necessidades educativas especiais, não possuindo contribuição concreta para os processos de ensino e aprendizagem de DV. Diferentemente da pesquisa aqui apresentada, a pesquisa abordada em [22], que tem por público alvo crianças autistas, tem por contribuição central a descrição dos processos de software desenvolvidos, não havendo preocupação maior com os processos de ensino e aprendizagem de DV. Por exemplo, se uma criança autista for deficiente visual ela não tem como utilizar o sistema. A principal contribuição apontada em [18] consiste na possibilidade de permitir a um terapeuta realizar um planejamento motor de uma criança através da colocação de marcadores no chão (ou numa mesa) por onde a criança irá se deslocar. O estudo de caso apresentado na pesquisa foi com uma criança de 5 anos com paralisia cerebral. Ao contrário da pesquisa aqui apresentada, não está proposta uma adaptação ou facilitação real para uso por DV: o reconhecimento visual de cores é fundamental para o andamento do jogo proposto.

Concernente às pesquisas correlatas cujo público alvo são DV, o sistema apresentado por [47], de modo diverso ao Geometrix, faz uso de sensores físicos (botões, fios, contatos elétricos etc.) que requerem ser instalados antes de uso, uma dificuldade adicional para DV. Ademais, o sistema não acompanha o dedo do usuário (como faz o Geometrix) apenas emite um sinal quando determinados pontos são tocados. Contrariamente à pesquisa aqui apresentada, [33] restringe o uso da ferramenta de construção de diagramas à utilização do teclado e ao leitor de tela e, por conseguinte, não é um ambiente propício para a aprendizagem e manipulações concretas de conceitos. Ademais, a navegação para a construção de diagramas se faz através de sequências de teclas pré-definidas que devem ser previamente conhecidas pelos usuários. Diferentemente do Geometrix, no qual a aprendizagem não requer conhecimentos e habilidades prévios, no sistema proposto por [34] o aluno deficiente visual tem por obrigação já conhecer a modelagem de dados uma vez que um diagrama será montado sempre a partir de informações que devem ser obrigatoriamente fornecidas pelo usuário. Além disso, afora as importantes limitações na elaboração de um DER, existe a necessidade de um professor cadastrar o enunciado detalhado de cada problema a ser proposto. Há necessidade de ajuste da velocidade do mouse para se conseguir que a movimentação na interface do protótipo proposto por [35] seja próxima do mouse real num mousepad especial (um modelo texturizado que é fundamental para que o protótipo funcione). Diversamente do Geometrix, o protótipo proposto já embute um custo inicial próprio e o deslocamento do mouse é insistentemente informado via um sintetizador de voz. Não há processos de aprendizagem e manipulações de conceitos, como acontece com o Geometrix, e o protótipo usa um editor de textos com certa dependência de teclas para a exibição de menus (na verdade, é informada uma equivalência entre teclas e menus que ajudam o usuário a usar teclas). Em [36] não existem processos de ensino e aprendizagem de per si, como acontece com o Geometrix, mas sim uma forma de treinamento visando a destreza no digitar do usuário com deficiência visual. Para isso ele usa métodos consagrados para o posicionamento de dedos e mãos no teclado, tomando as teclas ASDFG como referencia. 
No contexto de jogos educativos para pessoas portadoras de deficiência, [20] apresenta um jogo de estratégia de deslocamentos, aliado a um classificador NaïveBayesiano, que é utilizado para ajudar no processo de avaliação cognitiva do TDAH (Transtorno do Déficit de Atenção/Hiperatividade) em crianças e adolescentes. Um trabalho interessante sobre jogos educativos no contexto do SBIEs é apresentado por [19] e uma síntese sobre sistemas que fazem uso de tecnologias assistivas e pesquisas correlatas com foco em DV (de 1965 a 2009) é descrita por [26] (na realidade um trabalho de revisão de 256 artigos científicos dos quais apenas dois representaram um impacto pragmático relevante).

\section{O ambiente Geometrix}

O Geometrix tem por inspiração inicial o jogo matemático Cityvox [39] que faz uso de um tabuleiro contendo perguntas referentes à geometria espacial visando ensinar, de forma lúdica, os conceitos básicos de geometria (normalmente abordados no final do ensino fundamental). Foi precisamente durante o processo de experimentação do Cityvox junto a DV do IBC que se percebeu as enormes lacunas que existiam na formação daqueles $\mathrm{DV}$, lacunas estas que baseavam-se principalmente na falta de domínio de conceitos extremamente basilares da geometria. Não dominar esses conceitos representa claramente uma dificuldade em desenvolver uma habilidade adequada em reconhecer localizações espaciais e, mais incisivamente, em elaborar abstrações espaciais. O domínio desses conceitos (ainda que demasiadamente simples) é necessário para os jogadores poderem responder corretamente às perguntas do tabuleiro. Uma experimentação meticulosa com o Desenvox, na tentativa de auscultar melhor essas deficiências, não logrou êxito, notadamente pela falta de autonomia necessária em processos de ensino e aprendizagem de DV.

Foi justamente a partir dessas percepções, quando das experimentações do Desenvox e do Cityvox com DV, que surgiram as ideias basilares de se construir um ambiente dinâmico que pudesse ser utilizado em processos de ensino e aprendizagem de conceitos geométricos. O intento era que o novo ambiente se diferenciasse daqueles conhecidos até então, entre outras características, por um baixíssimo custo de implantação, por um grau de autonomia bastante significativo e, sobretudo, por proporcionar manipulações concretas de conceitos básicos da geometria. O objetivo pragmático foi o de que DV pudessem utilizar o novo ambiente sem dependência significativa de outrem. Precisamente fundamentado nessas ideias e visando atingir esses objetivos que foi projetado e implementado o ambiente Geometrix.

\subsection{Princípios educacionais do Geometrix}

Os princípios educacionais do Geometrix estão baseados tanto no construtivismo de Piaget, particularmente em seus estudos sobre o desenvolvimento mental iniciado nos primeiros anos de vida [37], quanto no construcionismo de Papert, especialmente no que se refere à construção do conhecimento a ser edificada a partir da interação do aluno com uma ferramenta (o computador, por exemplo) [38]. A formação da inteligência e da capacidade cognitiva, para Piaget, encontra-se diretamente imbricada às experiências físicas e à aptidão da criança compreender o "lógico-matemático". Isto significa a criança desenvolver seu conhecimento intermediado pela manipulação de objetos e, à medida que essa interação acontece, inferir conceitos (sem que os mesmos sejam efetivamente ensinados) através de seu "mecanismo de aprendizagem". Corroborando com essa ideia, Papert defende que inserindo-se uma ferramenta tecnológica no escopo educacional do aluno, de tal maneira que o desperte com uma motivação capaz de impulsioná-lo para "o querer aprender", o resultado será uma aprendizagem mais significativa e mais autônoma. Segundo Papert, essa abordagem construcionista só deverá ocorrer se a ferramenta inserida conseguir se enquadrar no ciclo "descrição-execução-reflexão-depuração-descrição", do qual a linguagem LOGO é um reconhecido exemplo.

Fundamentado portanto nesses conceitos, o ambiente Geometrix foi projetado focalizando principalmente dois princípios basilares: $i$. o usuário deve interagir com objetos do ambiente para conseguir desenvolver suas próprias conceitualizações (baseado no processo de assimilação e acomodação defendido por Piaget); ii. o usuário deve aprender a utilizar adequadamente os conceitos retidos sem que haja necessariamente uma interferência instrucional (baseado no construcionismo de Papert). Com efeito, a teoria construtivista e a abordagem construcionista formam a pedra angular dos princípios educacionais do Geometrix, notadamente para os diversos processos que se ativam durante uma seção de ensino e aprendizagem de conceitos geométricos, o que, por consequência, liberta os usuários DV, através do uso de tecnologias assistivas, tanto da necessidade premente de uso de artefatos unicamente táteis quanto da participação obrigatória de outrem, durante o processo de ensino e aprendizagem, para assisti-los em todos os eventos que impliquem numa necessidade visual. Assim sendo, o Geometrix corrobora para que DV passem a ter uma melhor oportunidade de aprender de per si, perpassando interferências externas, fundamentada no processo de exploração e descoberta.

\subsection{Os aspectos tecnológicos do Geometrix}

O Geometrix possui um artefato tecnológico bastante simplório e de baixíssimo custo. À sua concepção inicial 
foram adicionados mecanismos que pudessem resultar em simplificação de acessibilidade e de usabilidade. Desta forma, o Geometrix une elementos materiais e "elementos" computacionais em sua arquitetura de tal maneira que seu usuário consiga abstrair conceitos mais gerais a partir de experimentos particulares. O objetivo

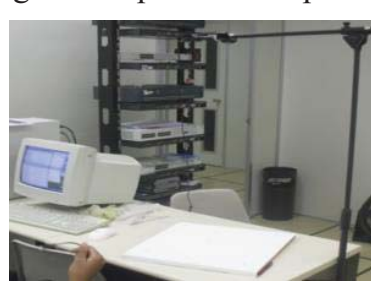

Figura 2: Arquitetura do Geometrix capital é que o ambiente possa oferecer uma tecnologia assistiva que possibilite DV a edificarem, a reterem e a aplicarem coerentemente conceitos geométricos, de forma autônoma. Os elementos computacionais do ambiente, além de um computador e do sistema de software que o compõe, são: $i$. Dosvox como uma ferramenta sonora interativa; ii. características de usabilidade do Desenvox; iii. ideias instrucionais programadas do Cityvox. Os elementos materiais do Geometrix são: $i$. Webcam; ii. pedestal; iii. Tabuleiro. O pedestal é extremamente modesto e pode ser substituído por qualquer artefato que consiga suspender ortogonalmente uma webcam acima do tabuleiro (denominado lidipad) que, por sua vez, é extremamente simples de ser construído (Figura 2).

A arquitetura tecnológica do Geometrix usa capturas de imagens para posterior reconhecimento de padrões. $\mathrm{O}$ uso de webcams para esses fins tem sido incentivado notadamente devido ao seu baixo custo [41], e pesquisas têm dado destaque à filtragem e tratamento de imagem visando melhorar as clássicas distorções da webcam (notadamente as cushion e barrel) [42], [43], [44]. Usando processos similares, a webcam do Geometrix é utilizada para capturar inicialmente a imagem do dedo do usuário, que é tratada a fim de identificar o posicionamento do dedo sobre o tabuleiro. À essa identificação associa-se um subsecutivo feedback sonoro para o usuário que informa-lhe o posicionamento de seu dedo.

\begin{tabular}{|c|c|}
\hline Módulo & Rotinas (06) \\
\hline $\begin{array}{l}\text { video: respon- } \\
\text { sável pelo cor- } \\
\text { reto posiciona- } \\
\text { mento da webcam } \\
\text { acima do tabu- } \\
\text { leiro. Este } \\
\text { posicionamento } \\
\text { é feito de for- } \\
\text { ma que os pon- } \\
\text { tos sobressa- } \\
\text { lentes do tabu- } \\
\text { leiro fiquem } \\
\text { dentro do foco } \\
\text { da webcam. Isto } \\
\text { permite à web- } \\
\text { cam capturar } \\
\text { todos os pontos } \\
\text { no tabuleiro. }\end{array}$ & $\begin{array}{l}\text { _init_: capta o caminho da } \\
\text { webcam (número da webcam, } \\
\text { mostra a webcam em tela } \\
\text { separada); } \\
\text { displayPropertyPage: retor- } \\
\text { na as propriedades; } \\
\text { displayCaptureFilterProper- } \\
\text { ties: responsável pelos } \\
\text { filtros; } \\
\text { setResolution: valora a } \\
\text { resolução; } \\
\text { getBuffer: captura a velo- } \\
\text { cidade de leitura; } \\
\text { getImage: captura uma ima- } \\
\text { gem; } \\
\text { savesnapshot: salva uma } \\
\text { imagem. }\end{array}$ \\
\hline
\end{tabular}

Tabela 1: O desenvolvimento do módulo video
O sistema de software que compõe o ambiente foi inteiramente desenvolvido sob a égide das regras da engenharia de software de tal forma que foram devidamente contemplados todos os processos de projeto, implementação e testes: engenharia de sistemas, análise de requisitos, projeto, codificação, validação e manutenção. A prototipagem necessária para se efetuar o estudo de campo realizado para a validação de conceito da proposta foi programada em Python 2.6 com a interface Pygame para o controle da webcam (640x480 pixels), da computação gráfica e do som. Utilizou-se um PC WXp, Pentium IV, 333MHz, 1Gb RAM, 40Gb HD e placa de som interna. O projeto e a implementação do sistema foram modularizados e soluções de caráter global foram reificadas numa única classe de tal forma que todos os processos executáveis estivessem consolidados e disponíveis para ativação durante a execução do sistema. A Tabela 1 ilustra os métodos do módulo video, a Tabela 2 os do módulo calibragem, e a Tabela 3 os do módulo opção_calibragem.

\begin{tabular}{|c|c|}
\hline Módulo & Rotinas $(06)$ \\
\hline $\begin{array}{l}\text { calibragem: respon- } \\
\text { sável pela calibra- } \\
\text { gem da webcam. As } \\
\text { marcações inicias } \\
\text { no tabuleiro servem } \\
\text { como guia (para } \\
\text { usuários e ambien- } \\
\text { te). À primeira } \\
\text { captura de imagem } \\
\text { solicita-se posici- } \\
\text { onar o dedo indica- } \\
\text { dor nas marcaços } \\
\text { via o padrão de } \\
\text { calibragem Z. São } \\
\text { retornadas as medi- } \\
\text { das (em pixels) } \\
\text { para a calibragem } \\
\text { da webcam. }\end{array}$ & $\begin{array}{l}\text {-init_: inicializa a web- } \\
\text { cam e captura a primeira } \\
\text { imagem do tabuleiro; } \\
\text { dedo: busca o posiciona- } \\
\text { mento dedo do usuário; } \\
\text { calib: liga os quatro } \\
\text { pontos extremos para exe- } \\
\text { cutar o processo de cali- } \\
\text { bragem; } \\
\text { calc: calcula o posiciona- } \\
\text { mento geométrico do último } \\
\text { ponto; } \\
\text { desenha: Adquire a veloci- } \\
\text { dade de leitura da webcam; } \\
\text { dtest: exibe os pontos de } \\
\text { calibragem na tela junto } \\
\text { coma visão da webcam. }\end{array}$ \\
\hline
\end{tabular}

Tabela 2: O desenvolvimento do módulo calibragem.

\begin{tabular}{l|l}
\hline \multicolumn{1}{c|}{ Módulo } & \multicolumn{1}{c}{ Rotinas (04) } \\
\hline opçãocalibragem: res- & -init_: captura ima- \\
ponsável por permitir o & gem do tabuleiro; \\
usuário escolher o tipo & calibcam: Calibra a \\
de calibragem: manual ou & partir do dedo nos \\
automática. A manual, & pontos em sequência \\
executada no primeiro & Z; \\
acesso, requer um viden- & calibmanual: Calibra \\
te para as marcações e & a partir de dados \\
enquadramento dos pontos & vindos do tabuleiro; \\
ao campo visual da web- & calibauto: Calibra \\
cam. A automática é vol- & automaticamente com \\
tada para DV que usam os & os dados anteriores \\
dados da primeira cali- & salvos num arquivo \\
bragem manual. & txt. \\
\hline
\end{tabular}

Tabela 3: O desenvolvimento do módulo opção-calibragem

Um módulo específico do sistema é o módulo responsável pelo cálculo do mapeamento inverso da projeção (warping). Com efeito, uma imagem capturada pela webcam a partir da filmagem do tabuleiro é na realidade uma projeção de um objeto em perspectiva, justamente para 
simular uma sensação visual (como acontece numa foto). Uma característica importante da perspectiva é que as distâncias representadas variam de acordo com a profundidade. Ou seja, as distâncias representadas na perspectiva referentes a objetos colocados mais longe são representadas com distâncias menores do que as distâncias referentes àqueles próximos. Uma propriedade interessante (utilizada em vários processos construtivos) é que linhas paralelas no objeto visualizado convergem todas para um único ponto na perspectiva (o ponto de fuga). Assim, uma imagem obtida de um quadriculado (Figura 3a) quando exibida em perspectiva não pode ser ponderada simplesmente como um resultado de uma interpolação bilinear (Figura 3b), mas sim com uma aparência similar à mostrada na Figura $3 \mathrm{c}$. O cálculo do mapeamento inverso consiste justamente em descobrir, a partir de um ponto da imagem (projeção), qual é o ponto no espaço que deu origem àquela projeção. A solução desse problema requer conceitualizacões e técnicas da geometria projetiva que normalmente são computacionalmente

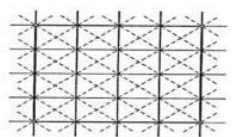

(a)

(a) Original

(b) Esquiespaçada

(c) Não Esquiespaçada

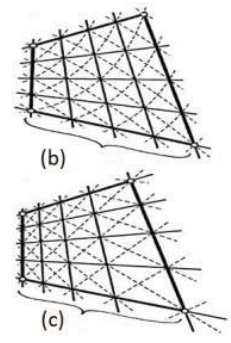

Figura 3: Exibição de quadriculado em perspectiva custosas e invalidariam os requisitos de desempenho do Geometrix. Para isto foram buscadas alternativas de solução que, ainda que não ótima do ponto de vista matemático, permitiu uma adequabilidade significativa do ambiente ao propósito de uso. A solução foi uma adaptação daquela proposta por [45], na qual uma câmera reconhece pontos de um polígono distorcido (imagem capturada de um retângulo focalizado não ortogonalmente) e os transforma em coordenadas canônicas. Ainda que o código fonte dessa solução contenha pouquíssimos comentários, pode ser depreendido, após uma análise detalhada, que os cálculos de warping são oriundos de uma solução matemática para mapeamento de texturas sobre superfícies [46] (utilizada amplamente em computação gráfica). Genericamente, a solução adotada consiste na resolução de um sistema de equações lineares descrito com base em oito parâmetros (coordenadas $x, y$ de quatro pontos do objeto mais os quatro pontos equivalentes na projeção). A partir desse sistema de equações, um ponto $x, y$ projetado em perspectiva, por exemplo, pode ser transformado em seu correspondente $x, y$ do objeto original.

Ainda que perpasse o objetivo do presente artigo, é mister de assinalar que a implementação adotada usou técnicas da álgebra linear cujas implementações mostraram-se bem eficientes. Utilizou-se basicamente um sis- tema de equações descrito por uma matriz de transformação que ao ser multiplicada por uma matriz coluna (representando as coordenadas da projeção) produz uma outra matriz coluna que contem a projeção. Essa manipulação matemática teve por base os cálculos inicialmente mostrados em [46]. Uma simplificação inicial adotada na implementação foi considerar que um objeto projetado é um objeto canônico, ou seja, os extremos são representados pelas coordenadas no intervalo [0,1]. Foi utilizada em seguida uma adaptação do algoritmo proposto em [46] de forma que a matriz de transformação pudesse ser adequadamente gerada. Essa matriz aplicada a um ponto $p_{p}=[x, y]$ de uma imagem projetada, leva-o a um ponto canônico $p_{c}=[u, v]$. Ou seja, os pontos $[x, y]_{p}$ serão os pontos capturados na imagem e os pontos $[u, v]_{c}$ serão os pontos aos quais eles se referem num tabuleiro canônico. Finalmente foi implementado o último módulo do sistema de software do Geometrix, o módulo principal, conforme ilustra a Tabela 4 .

Há de se sublinhar que todas as etapas do sistema estão permeadas por processos responsáveis pelos sons, através do sintetizador de voz, que são gerenciadas por um módulo suplementar chamado somwindows com uma única rotina de mesmo nome.

\begin{tabular}{|c|c|}
\hline Módulo & Rotinas \\
\hline $\begin{array}{l}\text { main: } \\
\text { invoca } \\
\text { todos os } \\
\text { módulos } \\
\text { com a } \\
\text { finalida- } \\
\text { de de } \\
\text { criar as } \\
\text { lógicas } \\
\text { dos exer- } \\
\text { cícios } \\
\text { para exe- } \\
\text { cutá-los } \\
\text { de forma } \\
\text { sistemá- } \\
\text { tica e } \\
\text { organizar } \\
\text { as telas } \\
\text { e menus } \\
\text { do Geome- } \\
\text { trix. }\end{array}$ & $\begin{array}{l}\text {-init_: carrega as imagens; } \\
\text { exercponto: funçoses de pontos do } \\
\text { tabuleiro demandados nas fases; } \\
\text { exerclinha: funços de linhas } \\
\text { (horizontais, verticais, diago- } \\
\text { nais) no tabuleiro demandadas nas } \\
\text { fases; } \\
\text { faseum; fasedois; fasetres; fase- } \\
\text { quatro; fasecinco; faseseis: ro- } \\
\text { tinas dos processos ativos das } \\
\text { fases 1 a 6; } \\
\text { desafio: lógica da fase desafio; } \\
\text { quad1: processos ativos da fase } \\
\text { quadrantesl; } \\
\text { quad2: processos ativos da fase } \\
\text { quadrantes2; } \\
\text { ang1: processos ativos da fase } \\
\text { ângulo1; } \\
\text { ang2: processos ativos da fase } \\
\text { ângulo2; } \\
\text { sc1: processos ativos da fase } \\
\text { seno/cossenol; } \\
\text { sc2: processos ativos da fase } \\
\text { seno/cosseno2; } \\
\text { sc3: processos ativos da fase } \\
\text { seno/cosseno3; } \\
\text { sc4: processos ativos da fase } \\
\text { seno/cosseno4; } \\
\text { sc5: processos ativos da fase } \\
\text { seno/cosseno5; } \\
\text { sc6: processos ativos da fase } \\
\text { seno/cosseno6; } \\
\text { update: processos ativos das po- } \\
\text { sições nas telas e de botões; } \\
\text { draw: desenha as imagens. }\end{array}$ \\
\hline
\end{tabular}

Tabela 4: O desenvolvimento do módulo main 


\subsection{Aspectos de uso do Geometrix}

O Geometrix propõe níveis que comportam distintos graus de dificuldades. A sua atual implementação (o Geometrix é objeto de constantes atualizações) possui dois níveis: NF (Nível Fundamental) e NM (Nível Médio). O NF engloba exercícios cujas resoluções são simples pois não exigem o domínio de conceitos geométricos mais elaborados. O NM contem exercícios com um grau de dificuldade um pouco mais elevado, cujas resoluções requerem um domínio mais significativo de conceitualizações geométricas.

No NF podem ser executadas até sete fases, das quais as seis primeiras abrangem exercícios sobre conceitos geométricos singelos, tais como criar retas e polígonos simples. A fase 7 comporta um jogo de localização de pontos geométricos e foi baseada no tradicional jogo Genius, no qual o jogador é constantemente desafiado a memorizar sequências de cores e de sons. A ideia subjacente desta fase é a de incutir no usuário a habilidade de memorização de conceitos e de poder finalizar o nível NF de uma forma cativante e lúdica. A Figura 4 ilustra o desenrolar da fase 5 do NF. O usuário deve usar o tabuleiro (seta 1) para desenhar o triângulo retângulo (apoiado por indicações vocais) e aparecerá na tela (seta 2) a pontuação atingida (os pontos verdes representam acertos

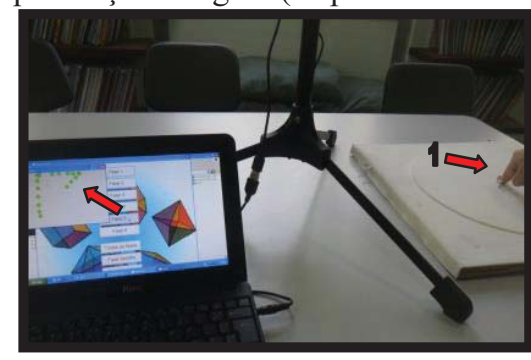

Figura 4: Fase 5 do NF:

conceitos sobre o triângulo retângulo e os pretos erros). Esta pontuação é informada vocalmente para o usuário.

No NM o objetivo central é ampliar e consolidar os conhecimentos obtidos no NF. Este nível encontra-se dividido em três seções: a seção 1 corresponde a exercícios sobre quadrantes, a 2 sobre ângulos e a 3 sobre trigonometria. Os exercícios da seção 1 testam as habilidades dos usuários concernentes a posicionamento do dedo em quadrantes demandados; os da seção 2 testam as habilidades em achar ângulos (indicados de forma contínua e de forma aleatória); os da seção 3 testam os conhecimentos obtidos sobre senos e cossenos de ângulos.

\section{Validação da hipótese: metodologia, instrumentos e estudo de campo}

No que se refere à metodologia adotada, ela suporta fundamentalmente as quatro etapas: $i$. levantamento de requisitos; ii. estudo piloto exploratório; iii. aplicação discente; $i v$. aplicação docente contextual.
Para a etapa de levantamento de requisitos ( $i$ ) foi efetuada uma criteriosa observação in loco das aulas de geometria, durante todo um ano letivo, que eram ministradas para as turmas de $8^{\circ}$ e $9^{\circ}$ anos para DV do IBC [8]. Neste período os requistos observados foram: $a$. materiais pedagógicos; $b$. metodologia de ensino; $c$. dificuldades na aprendizagem de conceitos geométricos; $d$. material de apoio acadêmico. O levantamento detalhado oriundo dessas observações foi fundamental para o desenvolvimento do ambiente porque ele proporcionou indicadores extremamente significativos para se idealizar as características básicas e as especiais que devem possuir um ambiente de ensino e aprendizagem de geometria para DV, consideradas as especificidades desses usuários. Findada a etapa de levantamento de requisitos fez-se necessário um período de maturação de ideias e de análises de pesquisas correlatas para se poder esquadrinhar o ambiente, levando em consideração os resultados obtidos com as observações advindas das salas de aulas do IBC. Subsequentemente a essa etapa elaborou-se o projeto e a implementação do sistema de software do ambiente (desenvolvimento do primeiro protótipo) visando a efetivação do estudo de campo. Há de se ressaltar que, em acordo com praticamente todas as pesquisas experimentais com sujeitos DV, uma grande (senão a maior) dificuldade da etapa de estudo de campo se refere à quase indisponibilidade de sujeitos que estejam capacitados (e também disponíveis) à participar do estudo. Por este motivo, a quantidade de sujeitos com deficiência visual levados em consideração em pesquisas de campo é, muito frequentemente, assaz diminuta.

A efetivação do estudo piloto exploratório (ii) baseou-se no uso do protótipo por dois grupos, um de controle e um experimental. O grupo de controle foi composto por alunos normovisuais e o grupo experimental por alunos DV. É mister de acrescentar que algumas experimentações com alunos normovisuais vendados foram efetuadas como uma forma de obter subsídios suplementares para o aprimoramento da adequação e do uso do ambiente. Este estudo piloto exploratório foi efetuado no CAEC (Centro de Apoio Educacional ao Cego) nas dependência do NCE (Núcleo de Computação Eletrônica) da UFRJ. Durante esta etapa um foco especial foi dado à adequação do protótipo às especificidades de seus usuários, a fim de se buscar características fidedignas que pudessem alavancar uma implementação de uma futura versão do ambiente contemplando o que havia sido exigido no levantamento de requisitos.

No que se refere aos instrumentos utilizados para a validação do conceito da proposta, foram desenvolvidos e aplicados quatro questionários distintos (Q1, Q2, Q3 e Q4). Q1 e Q3 foram aplicados numa etapa precedente à efetivação dos experimentos (Q1 aplicado aos professores de DV e de normovisuais e Q3 aos alunos DV e nor- 
movisuais). A finalidade principal destes se direcionava à obtenção de dados sóciodemográficos e relativos aos estudos, ou seja, identificação e análise de cenários de vida pessoal e acadêmica dos avaliados. Os dados então solicitados incluíam informações tais como: $a$ ) idade; $b$ ) sexo; c) deficiente visual ou não; $d$ ) grau de escolaridade; e) carga horária de trabalho; $f$ ) possuir computador; $g$ ) frequência de uso de computador; $h$ ) lecionar alunos DV; $i$ ) dificuldade acompanhamento de aulas de geometria; $j$ ) recursos utilizados em aula de matemática. Ao final do processo de experimentação propriamente dito foram aplicados Q2 e Q4 (Q2 aos professores de DV e de normovisuais e Q4 aos alunos DV e normovisuais) cujo objetivo capital era o de gerar subsídios fundamentais

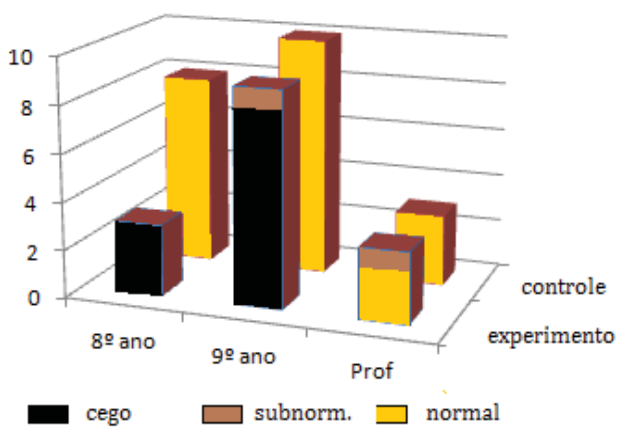

Figura 5: Distribuição de sujeitos nos grupos de controle e experimental. para validação do Geometrix, tais como: a) a tecnologia assistiva iguala DV a normovisuais em aprendizag em tradicional; b) Geometrix

pode ser manipulado por DV e normovisuais; c) Geometrix ajuda a aprendizagem e posicionamento espacial de DV; d) Geometrix facilita a compreensão de conceitos geométricos; e) Geometrix complementa as aulas de geometria. Q2 e Q4 são compostos por perguntas fechadas fundamentadas na escala de Likert com cinco variações, partido de "1. Não concordo totalmente" e crescendo até "5. Concordo totalmente". Estes questionários também possuem perguntas abertas para os pesquisados expressarem livremente suas opiniões, que foram analisadas sob um foco descritivo-interpretativo [8].

No que se refere ao estudo de campo, as aplicações discente (iii) e docente contextual (iv) foram especialmente importantes para a validação da pesquisa. $\mathrm{Na}$ aplicação discente aprofundou-se significativamente o uso de experimentos visando testar a adequabilidade do patamar de dificuldade do nível fundamental NF, enquanto que na aplicação docente contextual buscou a adequabilidade do grau de dificuldade do nível médio NM. Ou seja, a etapa de aplicação discente abordou mais especificamente os exercícios pertinentes ao NF, que se referem substancialmente a conceitos tais como ponto, reta, diagonais e polígonos regulares, enquanto a etapa de aplicação docente contextual abordou mais os exercícios concernentes ao NM que se referem substancialmente a conceitos mais elaborados da geometria tais como localizações espaciais, trigonometria (por simplificação foram tomados como referência os senos $/ \operatorname{cossenos~dos~ângulos~} 30^{\circ}, 45^{\circ}$ e $60^{\circ}$ ) e medida de ângulos (tomados como referência os ângulos $90^{\circ}, 180^{\circ}, 270^{\circ}$ e $\left.360^{\circ}\right)$. Esses conceitos ainda não haviam sido vistos pelos alunos DV do IBC, sujeitos da presente pesquisa $\mathrm{e}$, portanto, não poderiam ter sido abordados na aplicação discente e sim na aplicação docente contextual. Assim, o NF abrangeu seis exercícios e um estímulo de memorização via desafios de localização de pontos aleatórios enquanto o NM abrangeu dez exercícios aplicados ao docente contextual.

A etapa de aplicação discente foi realizada com dois grupos distintos de sujeitos do $8^{\circ}$ e $9^{\circ}$ anos classificados, conforme ilustra a Figura 5, como: alunos deficientes visuais (12); alunos normovisuais (18); professores de alunos normovisuais (3); professores de alunos deficientes visuais (3). As participações de todos os professores (05 videntes e 01 deficiente visual) em aplicação discente foram totalmente espontâneas e por eles requisitadas. Um efeito colateral extremamente positivo destas participações foi a contribuição conceitual fornecida que aprimorou características de exequibilidade das experimentações subsequentes. Os experimentos com o grupo de experimentação ocorreram nas dependências do IBC e com acompanhamento de outros professores. No que se refere aos processos utilizados nas aplicações para os sujeitos, foram estabelecidas as seguintes rotinas: $i$. informação sobre a proposta do ambiente; $i i$. apresentação dos artefatos físicos (tabuleiro, webcam, pedestal) que compõem o ambiente; iii. aplicação dos questionários Q1 e Q3; iv. realização da calibração da webcam; $v$. explanação contextual sobre o manuseio do ambiente; vi. execução de exercícios (sem intervenção); vii. aplicação dos questionários Q2 e Q4.

A etapa de aplicação docente contextual (apenas com DV) foi realizada com um professor, mestre em ciência da computação, com perda total de visão. A razão de se ter apenas um único sujeito deve-se, como apontado anteriormente, ao fato de que existem pouquíssimos DV que sejam professores habilitados, que dominem conceitos mais elaborados de geometria dinâmica e que (sobretudo) se mostre voluntário para participar de um estudo de campo que requer várias horas de aplicação. No entanto, na qualidade profissional do sujeito desta etapa sedimentou-se a qualidade das experimentações. Nesse sentido, ainda que a aplicação docente contextual tivesse por encargo trabalhar apenas com exercícios do NM, outros aspectos importantes foram suplementarmente analisados, entre os quais podem ser ressaltados: análise de precisão de execuções, velocidade de resposta, adequabilidade do exercício ao nível indicado, grau necessário de abstração na resoluções de exercícios e a qualidade da interação do usuário com o ambiente.

No que se refere à validação da hipótese, além da aplicação dos instrumentos descritivos-interpretativos, 
foram criados dois procedimentos suplementares visando aprimorar os processos de validação. Estes procedimentos são: $i$. estudo comparativo de desempenho dos discentes durante a resolução de exercícios; ii. análise dos dados constantes dos depoimentos dos sujeitos oriundos das respostas às questões discursivas (presentes em Q2 e Q4). Para o estudo comparativo $(i)$ foram consolidados dados representando o desempenho dos dois grupos (Tabela 5), aplicando-se uma escala com três níveis de classificação de desempenho (fácil, médio e difícil) com critérios de análise tais como exercícios concluídos, número de tentativas por fase, tempo médio de conclusão por fase etc. Para a análise dos dados (ii) foram escolhidos aleatoriamente algumas respostas discursivas (de discentes e docentes) e foi feita uma análise descritiva-interpretativa desses dados. Observa-se dos diversos dados deriváveis da Tabela 5 que na fase 4 (exercício de diagonais) entre 18 alunos videntes apenas 4 concluíram o exercício na $3^{\mathrm{a}}$. ou $4^{\text {a }}$. tentativa, enquanto 8 de $12 \mathrm{DV}$ precisaram de quatro tentativas ou desistiram. $\mathrm{Na}$ fase 7 , ainda que 10 alunos videntes e $2 \mathrm{DV}$ tenham conseguido atingir o nível 3, a maioria dos alunos teve desempenho meão e não concluiu a fase com sucesso. Finalmente, visando enriquecer e embasar algumas ponderações, determinadas informações da presente pesquisa foram também quantificadas. Um análise mais detalhada das fases, dos grupos e dos resultados obtidos estão mostrados em [8].
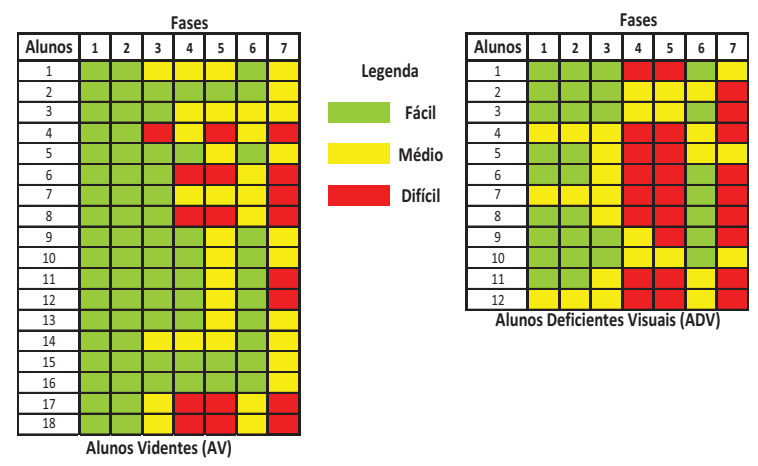

Tabela 5: Desempenho dos alunos videntes (AV) e deficientes visuais (ADV).

\section{Análise dos resultados}

No que se refere ao levantamento de requisitos, das análises dos resultados depreendem-se: $i$. deve ser de fácil manipulação, com sinalizadores táteis para auxiliar o manuseio do ambiente; ii. deve prover autonomia para realização de tarefas; iii. deve fornecer feedback sonoro para orientar DV; $i v$. deve servir como material de apoio para aulas de geometria. Baseado nessas análises de requisitos foi desenvolvido o primeiro protótipo do ambiente que foi informalmente experimentado (os aprimoramentos dele decorridos, muito advindos de tentativas e erros, foram paulatinamente adicionados). Foram ainda necessários mais três novos protótipos para que pudessem ser acatados plenamente os requisitos analisados. O quarto protótipo atendeu finalmente a todos requisitos e tornou-se o primeiro protótipo verdadeiramente satisfazível para os experimentos formais.

No que concerne ao estudo piloto exploratório foi efetivada a viabilidade do ambiente através de detecção, filtro e tratamento de imagens, tomando-se, inicialmente, apenas pontos do tabuleiro. Experimentos ulteriores mostraram que seria realmente plausível se reconhecer o dedo do usuário e calcular a sua posição espacial no tabuleiro. $\mathrm{O}$ passo seguinte foi ajustar coerentemente isto à fala do sintetizador de tal maneira que o usuário pudesse compreender o que estava sendo solicitado. Analisando os dados desses experimentos concluiu-se que o sincronismo do sintetizador de voz com os exercícios sendo executados ficou adequado, mas a detecção de pontos ainda deixava a desejar e precisava de um processo de refino. Análises de experimentos feitos a posteriori com usuários normovisuais vendados revelaram que as poucas instruções do ambiente de então eram quem estavam influenciando o resultado final e fazendo com que muitos DV não lograssem êxito nos exercícios. Disto deprecou a necessidade de inclusão de um conjunto significativo de novas instruções, o qual se mostrou eficaz em experimentações posteriores. Uma quarta bateria de experimentações foi efetivada, desta vez com DV que possuíam conhecimentos técnicos de computação. A análise desses experimentos levou à conclusão que o ambiente ainda necessitava de alguns detalhamentos funcionais para poder guiar adequadamente o usuário no uso do tabuleiro. Constatou-se também que o tempo de resposta do sistema poderia ser otimizado. Portanto, à medida que os experimentos eram realizados os ajustes foram sendo implementados gradativamente para, novamente, o ambiente ser testado. Ainda que essa ciclicidade tenha absorvido tempo e energia em demasia, as análises concernentes a essa bateria de testes mostraram-se extremamente promissoras e corroboraram finalmente para se chegar a uma versão completamente estável e adequada para ser experimentada por um conjunto mais significativo.

Em relação às etapas aplicação discente e aplicação docente contextual, cujos resultados detalhados e organizados pelos critérios avaliados estão mostrados em [8], as análises dos resultados advindos da aplicação dos questionários Q2 e Q4 mostram que:

$i$. o ambiente ajudou os alunos, principalmente os DV, na edificação, retenção e aplicação de conceitos abstratos, ensinando-os a aprimorarem a precisão em posicionamentos espaciais;

ii. o ambiente mostrou que pode efetivamente haver aprendizagem de conceitos de geometria de forma peremptória e autônoma (com sinalizadores sonoros e táteis suficientemente adequados para resolver exercícios sem 
ajuda de outrem).

iii. o ambiente inovou por propor uma nova maneira de aprender geometria, com características essencialmente interativas, alem de imprimir atividades lúdicas ao desenvolvimento do raciocínio matemático. As análises descritivas sobre reações dos usuários durante o uso do ambiente e, notadamente, a satisfação deles após as conclusões positivas das fases (muitas vezes pedindo para continuar experimentando o ambiente) confirmaram as características de um ambiente inovador e lúdico;

$i v$. as análises efetuadas em relação ao tempo de aquisição e ao uso adequado de conceitos geométricos levaram à conclusão comparativa de que o Geometrix tem uma performance superior ao ensino clássico em sala de aula. Com efeito, resultados mostraram que a execução de conjuntos de exercícios por DV utilizando o Geometrix (finalizando todas as fases) demandou, em média, 1/5 do tempo utilizado em sala de aula tradicional para resolver os mesmos conjuntos.

Algumas análises descritivas-interpretativas foram adicionalmente feitas em instrumentos suplementares aos descritos na seção 4. Foi elaborado um levantamento de opiniões sobre a adequação e o uso do ambiente envolvendo todos os sujeitos e colhidas imediatamente após eles terem finalizados os experimentos. Este levantamento tinha por ideia central a de se poder evidenciar a veracidade da hipótese da pesquisa. Ele trazia em seu bojo questionamentos que pudessem tanto refletir o imaginário dos professores (após assistirem uma aplicação do Geometrix em sala de aula) quanto evidenciar a percepção deles em relação à aplicabilidade própria do ambiente. Essas análises mostraram que o ambiente corrobora efetivamente para a edificação de conceitos abstratos a partir de experimentos pontuais e, particularmente, habilita a aplicação adequada dos conceitos aprendidos. Algumas marcações em relevo no tabuleiro serviram para certificar que elas proporcionam maior facilidade para executar inferências e absorver conceitos geométricos, resultando numa autonomia mais significativa. O ganho cognitivo constatado através de testes ulteriores foi peremptório e evocado em inferências e conclusões subsequentes. $\mathrm{O}$ suporte a feedbacks sonoros facilitou a aprendizagem construtivista fazendo com que inferências e induções pudessem ser elaboradas sem o auxílio de intervenções normovisuais, um aspecto fundamental na validação da hipótese. A característica construcionista do ambiente permitiu uma edificação de conhecimentos justamente a partir da interação com a máquina, ladeada pelos feedbacks de suporte às resoluções de exercícios. A autonomia, baseada na aquisição de conhecimentos pela descoberta, e o uso adequado de conceitos adquiridos na resolução de exercícios, permitem de asseverar que o uso do ambiente contribui significativamente para a edificação, retenção e aplicação de conceitos abstratos.

\section{Conclusões}

Este artigo apresentou um novo ambiente dinâmico para o ensino de geometria a deficientes visuais. A hipótese comprovada foi a de que a utilização de ambientes computacionais dinâmicos na educação de deficientes visuais pode corroborar substancialmente na edificação, fixação e aplicação de conceitos abstratos. Constatou-se ladeadamente que a utilização de ambientes de geometria pode aprimorar o posicionamento espacial, uma habilidade imprescindível para o deslocamento físico de um deficiente visual. Foram também apresentadas algumas análises sobre trabalhos correlatos visando situar a presente proposta em patamares referenciais teóricos e práticos, enfocando, entre outras coisas, os aspectos de uso e de adequação do sistema à dinâmica de ativação de processos em escopos reais de ensino e aprendizagem. Este artigo também detalhou os princípios educacionais do novo ambiente, fundamentados no construtivismo de Piaget e no construcionismo de Papert.

O estudo de campo para a validação do conceito da proposta foi efetuado com dois grupos (um de controle e um de experimentação) e dos resultados obtidos pode-se coligir que o ambiente ajudou efetivamente os alunos (notadamente os deficientes visuais) na edificação, retenção e futura aplicação de conceitos abstratos, alem de proporcionar um aprimoramento de suas habilidades em posicionamentos espaciais. Uma inovação importante apontada pelo uso do ambiente foi a maneira singular de aprender geometria utilizando técnicas assistivas essencialmente interativas, com atividades lúdicas, e que puderam proporcionar um aprendizado adequado e peremptório. Dimanou do estudo de campo também que o ambiente, no que concerne ao uso adequado de conceitos geométricos adquiridos pelos alunos deficientes visuais, tem uma performance bem superior ao ensino tradicional de sala de aula.

Como metas de trabalhos futuros sugere-se realizar: $i$. aumentar o número de conceitos geométricos que podem ser abordados pelo ambiente, aquilatando a inclusão de novos exercícios; ii. incluir algoritmos mais ágeis de reconhecimento de imagens visando aplicações em tempo real mais sofisticadas; iii. realizar uma análise de "crosstalk" visando delimitar os erros que ocorrem devido às interferências entre os conteúdos exercitados; $i v$. aumentar a ludicidade do ambiente inserindo mais jogos com animações nas quais o tabuleiro sirva como controlador de ação/direção; iv. ampliar a metodologia do ambiente para outras áreas tais como o ensino da física e da geografia. 


\section{Referências}

[1] Instituto Benjamin Constant. http://www.ibc.gov.br/. Acessado em: $12 / 03 / 2013$.

[2] J. W. Creswell. Qualitative inquiry and research design. Sage Publications Inc, Second Edition. Thousand Oaks, CA, USA, 2007.

[3] J. W. Willis. Foundations of qualitative research: interpretative and critical approaches. Sage Publications Inc, Thousand Oaks, CA, USA, 2007.

[4] M. J. G. S. Tanbellini, L. O. Brandão. O uso da geometria interativa como facilitador no ensino e aprendizagem de matemática: estudo com duas turmas de sexta série do ensino fundamental. Anais do XXI SBIE - XVI WIE Simpósio Brasileiro de Informática na Educação, 1245-1254, 2010 .

[5] L. Z. Pedro, S. S. Borges, A. M. Z. Lopes, J. P. T. Souza. Projeto e desenvolvimento de um aplicativo de geometria interativa para dispositivos móveis. Anais do XXIII Simpósio Brasileiro de Informática na Educação, 2012.

[6] J. A. Edwards, K. Jones. Linking geometry and algebra with GeoGebra. Mathematics Teaching, 194, 28-30, 2006.

[7] Portal of Mathematical Collaboration. Disponível em: http://tabulae.net/pcm/. Acessado em: 25/02/2013.

[8] L. F. Silva. Geometrix: ensinando conceitos geométricos a deficientes visuais. Dissertação de mestrado em informática. Universidade Federal do Rio de Janeiro, 2011.

[9] M. Satterfield. Geometer's Sketchpad: single user package, version 3. Mathematics, Teaching in the Middle School. 7(3): 184-194, 2001.

[10] M. Hohenwarter, J. Hohenwarter. Ways of linking geometry and algebra: the case of Geogebra. In: D. Küchemann (eds.) Proceedings of the British Society for Research into Learning Mathematics. 27(3): 126-131, 2007.

[11] E. B. Ferreira, A. B. Soares, C. Lima. Aprimoramento conceitual e uso de demonstrações matemáticas: um estudo de caso sobre a geometria dinâmica e as pesquisas de campo com ambientes computacionais de ensino. Revista Brasileira de Informática na Educação. 20(3): 13-25, 2012.
[12] F. H. Ho, Y. H. Leong. Using dynamic geometry software in teaching geometry proof. In: Proceedings of the 5th East Asia Regional Conference on Mathematics Education, 2010. http://hdl.handle.net/10497/4473. Acessado em: 07/07/12.

[13] J. Zhang, X. Peng, M. Chen. Practice and thinking about teaching dynamic geometry course in normal university. Electronic Journal of Mathematics and Technology. 4(2): 1-15, 2010.

[14] L. O. Brandão, S. Isotani, J. G. Moura. Imergindo a geometria dinâmica em sistemas de educação a distância: IGEOM e SAW. Revista Brasileira de Informática na Educação. 14(1): 41-49, 2006.

[15] C. Lima, A. B. Soares, G. Alves. Geometric visualization: how to acquire it using dynamic geometry systems? In: Proceedings of the Third International Conference on System ICONS. (1): 306-311, 2008.

[16] N. J. Wildberger. Divine proportions: rational trigonometry to universal geometry. Sydney, Wild Egg, ISBN 0-9757492-0-X, 2005.

[17] S. L. Araújo, K. P. Benassi. O uso dos recursos da informática como instrumento mediador no processo de ensino-aprendizagem de pessoas com necessidades educativas especiais: um relato de experiência. Revista Brasileira de Informática na Educação. 13(2): 65-70, 2005.

[18] A. G. Corrêa, G. A. Assis, M. Nascimento, R. D. Lopes. GenVirtual: um jogo musical para reabilitação de indivíduos com necessidades especiais. Revista Brasileira de Informática na Educação. 16(1): 09-17, 2008.

[19] M. H. Pietruchinski, J. C. Neto, A. Malucelli, S. Reinehr. Os jogos educativos no contexto do SBIE: uma revisão sistemática de literatura. Anais do XXII SBIE - XVII WIE Simpósio Brasileiro de Informática na Educação, 476-485, 2011.

[20] A. P. Bastos, F. Santos, L. Andrade, P. Mattos. Utilização de um jogo sério e Naïve Bayes para auxiliar na avaliação cognitiva do transtorno de déficit de atenção/hiperatividade. Anais do XXIII Simpósio Brasileiro de Informática na Educação, 2012.

[21] M. V. Paula, G. A. Ferreira, R. A. Silva. Uma análise exploratória do uso da realidade aumentada por pessoas com necessidades educativas especiais. Anais do XXIII Simpósio Brasileiro 
de Informática na Educação, 2012.

[22] F. R. Sousa, E. B. Costa, T. C. Castro. WorldTour: Software para Suporte no Ensino de Crianças Autistas. Anais do XXIII Simpósio Brasileiro de Informática na Educação, 2012.

[23] C. Kamei-Hannan, J. Howe, R. R. Herrera, J. N. Erin. Perceptions of teachers of students with visual impairments regarding assistive technology: a follow-up study to a university course. Journal of Visual Impairment \& Blindness. 106(10): 666-678, 2012.

[24] A. L. Freeland, R. W. Emerson, A. B. Curtis, K. Forgaty. Exploring the relationship between access technology and standardized test scores for youths with visual impairments: Secondary analysis of the National Longitudinal Transition Study-2. Journal of Visual Impairment \& Blindness. 104(3): 170-182, 2010.

[25] S. M. Kelly. Use of assistive technology by students with visual impairments: findings from a national survey. Journal of Visual Impairment \& Blindness. 103(8): 470-480, 2009.

[26] S. M. Kelly, D. W. Smith. The impact of assistive technology on the educational performance of students with visual impairments: A synthesis of the research. Journal of Visual Impairment \& Blindness. 105(2): 73-83, 2009.

[27] A. Edwards, H. McCartney, F. Fogarolo. Lambda: a multimodal approach to making mathematics accessible to blind students. In: Proceedings of the 8th International ACM SIGACCESS Conference on Computers and Accessibility. (1): 48-54, 2006.

[28] D. Crombie, R. Lenoir, N. McKenzie, A. Barker. Math2braille: opening access to mathematics. In: Proceedings of the International Conference on Computers Helping People with Special Needs. (1): 670-677, 2004

[29] P. B. Atanley, A. I. Karshmer. Translating MathML into Nemeth Braille code. In: Proceedings of the International Conference on Computers Helping People with Special Needs. (1): 1175-1182, 2006.

[30] N. Soiffer. Mathplayer: web-based math accessibility. In: ASSETS3905 ACM Press, 2005.

[31] J. A. Borges. Do Braille ao Dosvox: diferenças nas vidas dos cegos brasileiros. Tese de Doutorado em Ciências em Engenharia de Sistemas e Computação. Universidade Federal do Rio de
Janeiro, 2008

[32] J. A. Borges, P. M. Barbosa, L. R. Jansen, S. B. Lyrio. Desenvox: computer tools to teach basic geometry and drawing for the visually disabled. In: $200811^{\text {th }}$ International Congress on Mathematical Education. Disponível em: http://www.ibc.gov.br/. Acessado em: $15 / 03 / 2013$.

[33] L. G. Santos, A. M. Bandeira, L. T. Pansanato, D. B. Paiva. Recursos de acessibilidade para auxiliar a navegação de estudantes cegos em um editor de diagramas. Anais do XXIII Simpósio Brasileiro de Informática na Educação, 2012.

[34] R. L. Magalhães, M. F. Neto. AprenDER: Ferramenta de apoio à construção de diagrama entidade relacionamento para deficientes visuais. Anais do XXI Simpósio Brasileiro de Informática na Educação, 2010.

[35] S. M. Camargo Filho, F. Bica. Acessibilidade digital para cegos: um modelo de interface para utilização do mouse. Anais do XX Simpósio Brasileiro de Informática na Educação, 2009.

[36] N. C. Albernaz, M. F. Elia, J. A. Borges. Digitavox: curso de digitação com acessibilidade para deficientes visuais. Anais do XXII Simpósio Brasileiro de Informática na Educação, 558-567, 2011.

[37] PIAGET, Jean. Seis estudos de psicologia. Trad. Maria Alice Magalhães D"Amorim e Paulo Sergio Lima Silva. 21. ed., Rio de Janeiro: Forense Universitária, 1995.

[38] PAPERT, S. Constructionism: A new opportunity for elementary science education. Massachusetts Institute of Technology, 1986.

[39] L. F. Silva. Geometria e cegos: um jogo computacional no processo de aprendizagem de trigonometria. Monografia de pós-graduação em tecnologias da informação aplicadas à educação. Universidade Federal do Rio de Janeiro, 2009.

[40] PAPERT, S. A máquina das crianças: repensando a escola na era da informática. Artes Médicas. 1994.

[41] R. G. Monteiro, C. Lima, A. C. Thomé. Detecção da direção do olhar via webcam. WTDSIBGRAPI 25th Conference on Graphics, Patterns and Images, 2012.

[42] J. Mallon, P. F. Whelan. Precise radial undistortion of images. In: Proceedings of the 17th International Conference on Pattern Recogni- 
tion. (1): 18-21, 2004.

[43] M. A. Flores, A. C. Thomé, C. Lima, A. J. Cruz. A dynamic fluid level monitoring application using Hough transform and edge enhancement. In: Proceedings of the IEEE International Symposium on Industrial Electronics. 317-332, 2009.

[44] T. H. Ngo, V. V. Asari. A pipelined architecture for real-time correction of barrel distortion in wide-angle camera images. IEEE Transactions on Circuits and Systems for Video Technology. 15(3): 436-444, 2005.

[45] J. C. Lee. Projector-based location discovery and tracking. Ph.D. Thesis. Carnegie Mellon University, 2008.

http://johnnylee.net/projects/thesis/thesis_docum ent.pdf. Acessado em 04/09/2012.

[46] P. S. Heckbert. Fundamentals of texture mapping and image warping. M.Sc. Thesis. University of California, Berkeley, 1989.

[47] S. H. Ventorini. A experiência como fator determinante na representação espacial do deficiente visual. Dissertação de Mestrado, UNESP Rio Claro, 2007. 